\title{
Optimized Nuclear Pellet Method for Extracting Next-Generation Sequencing Quality Genomic DNA from Fresh Leaf Tissue
}

\author{
Md Masud Rana ${ }^{1,2}$, Murat Aycan ${ }^{3}{ }^{(}$, Takeshi Takamatsu ${ }^{1,3}$, Kentaro Kaneko ${ }^{1}$, \\ Toshiaki Mitsui 1,3 (D) and Kimiko Itoh 1,3,*(D) \\ 1 Department of Life and Food Sciences, Graduate School of Science and Technology, Niigata University, \\ Niigata 950-2181, Japan; f16m502g@mail.cc.niigata-u.ac.jp (M.M.R.); takamatsutakeshi@yahoo.co.jp (T.T.); \\ k-neko@gs.niigata-u.ac.jp (K.K.); t.mitsui@agr.niigata-u.ac.jp (T.M.) \\ 2 Agronomy Division, Bangladesh Rice Research Institute, Gazipur-1701, Bangladesh \\ 3 Institute of Science and Technology, Niigata University, Niigata 950-2181, Japan; \\ murataycan@agr.niigata-u.ac.jp \\ * Correspondence: kimi@agr.niigata-u.ac.jp; Tel.: +81-25-262-7522
}

Received: 13 March 2019; Accepted: 21 June 2019; Published: 25 June 2019

\begin{abstract}
Next-generation sequencing (NGS) is a revolutionary advancement allowing large-scale discovery of functional molecular markers that has many applications, including plant breeding. High-quality genomic DNA (gDNA) is a prerequisite for successful NGS library preparation and sequencing; however, few reliable protocols to obtain such plant gDNA exist. A previously reported nuclear pellet (NP) method enables extraction of high-yielding gDNA from fresh leaf tissue of maize (Zea mays L.), but the quality does not meet the stringent requirements of NGS. In this study, we optimized the NP method for whole-genome sequencing of rice (Oryza sativa L.) through the integration of simple purification steps. The optimized NP method relied on initial nucleus enrichment, cell lysis, extraction, and subsequent gDNA purification buffers. The purification steps used proteinase K, RNase A, phenol/chloroform/isoamyl alcohol (25:24:1), and chloroform/isoamyl alcohol (24:1) treatments for protein digestion and RNA, protein, and phenol removal, respectively. Our data suggest that this optimized NP method allowed extraction of consistently high-yielding and high-quality undegraded gDNA without contamination by protein and RNA. Moreover, the extracted gDNA fulfilled the quality metrics of NGS library preparation for the Illumina HiSeq X Ten platform by the TruSeq DNA PCR-Free Library Prep Kit (Illumina). We provide a reliable step-by-step guide to the extraction of high-quality gDNA from fresh leaf tissues of rice for molecular biologists with limited resources.
\end{abstract}

Keywords: DNA extraction; high-quality gDNA; next-generation sequencing

\section{Introduction}

Next-generation sequencing (NGS) is an advancement in molecular biology that allows the detection of thousands of nucleotide variations and the development of functional molecular markers in various plant species regardless of their genome size [1]. These markers have been used successfully in plant breeding to improve economically important agronomic traits from multiple crop species. NGS involves several high-throughput sequencing technologies, such as Illumina, Ion Torrent, PacBio, and Oxford Nanopore [1]. Library preparation, sequencing runs, sequence validity, and the number of reads in these technologies depend mostly on the purity and quality of the genomic DNA (gDNA) [2,3]. In recent years, NGS technologies have become popular with molecular biologists due to their low cost, high accuracy, and reliability. The gDNA for NGS must meet strict quality control 
(QC) requirements, including high molecular weight; an intact and undegraded structure upon gel electrophoresis; an $A_{260} / A_{280}$ ratio of 1.8-2.0 (indicating purity); and a lack of contamination from secondary metabolites, phenols, and RNA [2,4,5]. Using undegraded DNA is the key to obtaining longer sequencing reads in third-generation sequencers [6,7]. The isolation of high-purity gDNA also improves the accuracy and cost efficiency of high-throughput sequencing.

The hexadecyltrimethylammonium bromide (CTAB) method is a widely used gDNA extraction protocol [8] that is applicable to diverse samples. In the last few years, a significant number of gDNA extraction methods from plant tissues have been published [2,3,7,9-13]. Some of these either modified or improved the traditional CTAB-based method, targeting improved yields and quality. There are, however, few published reports demonstrating the efficiency of gDNA extraction procedures from plant samples for NGS applications. In addition, the isolation of gDNA for downstream genetic analysis using the available commercial kits is expensive and not suitable for all species. However, reliable protocols to obtain high-quality plant genomic DNA are few, impeding NGS technologies and further functional genomics research. The quality of gDNA and its integrity are crucial for most downstream applications in PCR [14] and high-throughput technologies [2,3]. The purity of DNA varies according to the extraction method and tissue source [15]. gDNA purification from plants can be problematic due to contamination from proteins, polysaccharides, residual phenols, and ribonucleotides. The gDNA could be purified from these contaminants through digestion and precipitation using proteinase $\mathrm{K}$, a mixture of phenol and chloroform, and RNase A treatments. Many commercial gDNA purification kits are also available and suitable for a variety of applications.

The nuclear pellet (NP) method enables the extraction of high-yielding gDNA from fresh leaf tissues of maize (Zea mays L.) and relies mostly on grinding, cell lysis, and DNA precipitation buffers [16]. The gDNA of the NP method is suitable for PCR-based assays [17] but has not been sufficiently optimized for NGS analysis.

Here, we optimized the NP method for extraction of rice (Oryza sativa L.) gDNA by integrating some simple purification steps. We assessed and compared the yield, quality, and integrity of extracted DNA using the optimized NP method with the CTAB-based QIAGEN DNeasy Plant Mini Kit and NP protocols, using fluorometric and qubit measurements and gel electrophoresis. Furthermore, the gDNAs from the optimized NP method were sequenced on the Illumina Hiseq $X$ Ten platform with NGS libraries prepared by the TruSeq DNA PCR-Free Library Prep Kit (Illumina) to evaluate the quality of the sequenced data.

\section{Materials and Methods}

\subsection{Plant Materials}

Seeds of the rice variety "Yukinko-mai" were sterilized with 2.5\% sodium hypochlorite, rinsed with water, and incubated at $28{ }^{\circ} \mathrm{C}$ for two days in the dark. Pregerminated seeds were then grown in the seedling tray. Twenty-day-old rice seedlings were used for the extraction of gDNA.

\subsection{Genomic DNA Extraction}

\subsubsection{CTAB-Based Method}

Genomic DNA was extracted using the CTAB-based method [8] with some modifications. Fresh leaf samples (100 mg) were frozen in liquid nitrogen and ground to a fine powder using a mortar and pestle. The CTAB extraction buffer (1.4 M NaCl, 100 mM Tris- $\mathrm{HCl}$ pH 8.0, 20 mM EDTA pH 8.0, 2\% CTAB) was then added. After incubation at $65^{\circ} \mathrm{C}$ for $1 \mathrm{~h}$, purification with phenol:chloroform:isoamyl alcohol (25:24:1) and DNA precipitation with isopropanol was performed. The DNA pellet was washed with $1 \mathrm{~mL}$ of $70 \%$ ethanol and air-dried. Finally, the DNA pellet was resuspended in $100 \mu \mathrm{L}$ Milli Q water. After suspension, $1 \mu \mathrm{L}$ of RNase A (10 ng) was added and incubated for $30 \mathrm{~min}$ at $37^{\circ} \mathrm{C}$. 
The experiment used three biological replicates, each with a $100 \mathrm{mg}$ leaf sample, and the final gDNA concentration was calculated for a $1 \mathrm{~g}$ sample.

\subsubsection{Qiagen Method}

Genomic DNA from rice leaf tissue (100 mg) was extracted using the DNeasy Plant Mini Kit (Qiagen, Valencia, CA, USA) according to the manufacturer's protocol. The experiment used three biological replicates, each with a $100 \mathrm{mg}$ leaf sample, and the final gDNA concentration was calculated for a $1 \mathrm{~g}$ sample.

\subsubsection{Optimization of Nuclear Pellet Method}

Reagents

- Solution I: $15 \%$ sucrose, $50 \mathrm{mM}$ Tris- $\mathrm{HCl}$ (pH 8.0), $50 \mathrm{mM}$ EDTA (pH 8.0), and $500 \mathrm{mM} \mathrm{NaCl}$

- Resuspension buffer: 20 mM Tris- $\mathrm{HCl}$ (pH 8.0) and 10 mM EDTA (pH 8.0)

- $20 \%$ sodium dodecyl sulfate (SDS)

- $\quad 7.5 \mathrm{M}$ ammonium acetate

- $\quad 5 \mathrm{M} \mathrm{NaCl}$

- Isopropanol

- TE buffer: $10 \mathrm{mM}$ Tris-HCl (pH 7.6) and 0.1 mM EDTA

- RNase A: a working solution of $1 \mu \mathrm{g} / \mu \mathrm{L}$ (final concentration $\approx 10 \mathrm{ng} / \mu \mathrm{L}$ )

- Proteinase $\mathrm{K}$ : a working solution of $2 \mu \mathrm{g} / \mu \mathrm{L}$ (final concentration $\approx 80 \mathrm{ng} / \mu \mathrm{L}$ )

- $\quad$ PCI: phenol/chloroform/isoamyl alcohol (25:24:1)

- CIA: chloroform/isoamyl alcohol (24:1)

- $100 \%$ ethanol $(v / v)$

- $70 \%$ ethanol $(v / v)$

- Qubit $^{\mathrm{TM}}$ dsDNA HS Assay Kit (Thermo Fisher Scientific Inc., Waltham, MA, USA)

Equipment

- Mortar and pestle

- Dry block heater

- Table-top high-speed microcentrifuge

- Freezer $\left(-20^{\circ} \mathrm{C}\right)$

- Gel electrophoresis system

- Eppendorf BioSpectrometer ${ }^{\circledR}$ fluorescence (Eppendorf AG, Hamburg, Germany)

Note: Prepare all reagents using Milli Q water; autoclave glassware before use.

Protocol

The protocol for gDNA extraction using the optimized NP method is as follows and is shown schematically in Figure 1:

1. Weigh $1 \mathrm{~g}$ of young fresh leaf tissue and cut into small pieces using clean and sharp scissors. Place the cut tissue in liquid nitrogen and grind thoroughly with a mortar and pestle. Add $12 \mathrm{~mL}$ of Solution I to the fine tissue powder and suspend well. Transfer the suspended tissue $(2 \mathrm{~mL}$ in each) into six individual $2 \mathrm{~mL}$ microcentrifuge tubes.

2. Centrifuge the tubes containing the suspended tissue at $500 \mathrm{rpm}$ for $3 \mathrm{~min}$ at $4{ }^{\circ} \mathrm{C}$. Discard the upper phase carefully. Centrifuge at $1000 \mathrm{rpm}$ for $1 \mathrm{~min}$ at $4{ }^{\circ} \mathrm{C}$ and discard the upper phase.

3. Add $450 \mu \mathrm{L}$ of resuspension buffer and $30 \mu \mathrm{L}$ of $20 \%$ SDS into each tube containing tissue, shake briefly, and incubate at $70{ }^{\circ} \mathrm{C}$ for $15 \mathrm{~min}$. 
4. Add $230 \mu \mathrm{L}$ of $7.5 \mathrm{M} \mathrm{NH}_{4} \mathrm{OAc}$ into each tube, shake vigorously, and incubate the reaction mixture on ice for at least $30 \mathrm{~min}$.

5. Centrifuge the reaction mixture at $15,000 \mathrm{rpm}$ for $20 \mathrm{~min}$ at $4{ }^{\circ} \mathrm{C}$ and divide equal amounts of the cleared supernatant into six individual microcentrifuge tubes, labeled \#1-6. Repeat this step (once).

6. Add 1 volume of isopropanol to the supernatant of each tube, gently mix by inverting, and centrifuge at $15,000 \mathrm{rpm}$ for $15 \mathrm{~min}$ at $25^{\circ} \mathrm{C}$. Discard the supernatant and air-dry pellet for 5-10 min (do not excess dry).

7. Add $50 \mu \mathrm{L}$ of TE buffer individually to tubes \#1-5 and wait until the pellet has dissolved. Transfer the dissolved DNA from tubes \#1-5 into tube \#6. Add $50 \mu \mathrm{L}$ TE buffer to the original tube \#1, allow to dissolve, then transfer it to tube \#2. Repeat this transfer and dissolving process until tube \#5, then transfer the DNA to tube \#6. The final volume of the DNA sample in tube \#6 will be $300 \mu \mathrm{L}$.

8. Add $600 \mu \mathrm{L}$ of $100 \%$ ethanol to the sample in tube \#6, centrifuge at $15,000 \mathrm{rpm}$ for $10 \mathrm{~min}$ at $25^{\circ} \mathrm{C}$, and decant the supernatant. Again, add $600 \mu \mathrm{L}$ of $100 \%$ ethanol to the DNA pellet in tube \#6, centrifuge at 15,000 rpm for $1 \mathrm{~min}$, and decant the supernatant.

9. Air-dry the pellet for 5-10 min. Resuspend the pellet in $50 \mu \mathrm{L}$ of TE buffer (do not vortex).

10. Add $0.5 \mu \mathrm{L}$ of RNase A to the solution and incubate at $37^{\circ} \mathrm{C}$ for $1 \mathrm{~h}$.

11. Add $2.2 \mu \mathrm{L}$ of proteinase $\mathrm{K}$ to the solution and incubate at $37^{\circ} \mathrm{C}$ for $1 \mathrm{~h}$.

12. Check gDNA quality by electrophoresis using a $0.7 \%$ agarose gel (optional).

13. Add $400 \mu \mathrm{L}$ of TE buffer to the digested sample containing the DNA and mix gently by pipetting.

14. Add $450 \mu \mathrm{L}$ of PCI to the DNA solution, gently mix, and centrifuge at $15,000 \mathrm{rpm}$ for $15 \mathrm{~min}$ at $4{ }^{\circ} \mathrm{C}$. Transfer the cleared supernatant to a new $1.5 \mathrm{~mL}$ collection tube. Repeat this step (once).

15. Add $450 \mu \mathrm{L}$ of CIA to the DNA solution, mix gently, and centrifuge at 15,000 rpm for $15 \mathrm{~min}$ at $4{ }^{\circ} \mathrm{C}$. Transfer the cleared supernatant to a new $1.5 \mathrm{~mL}$ collection tube. Repeat this step (once).

16. Add $27 \mu \mathrm{L}$ of $5 \mathrm{M} \mathrm{NaCl}$ and $1 \mathrm{~mL}$ of $100 \%$ ethanol to the solution, gently mix, and incubate at $-20{ }^{\circ} \mathrm{C}$ for $1 \mathrm{~h}$.

17. Centrifuge at $15,000 \mathrm{rpm}$ for $15 \mathrm{~min}$ at $4{ }^{\circ} \mathrm{C}$ and discard the supernatant.

18. Wash the pellet with $100 \mu \mathrm{L}$ of $70 \%$ ethanol, centrifuge at $15,000 \mathrm{rpm}$ for $5 \mathrm{~min}$, and discard the ethanol.

19. Wash the pellet with $100 \mu \mathrm{L}$ of $100 \%$ ethanol, centrifuge at $15,000 \mathrm{rpm}$ for $5 \mathrm{~min}$, and discard the supernatant. Again, add $100 \mu \mathrm{L}$ of $100 \%$ ethanol to the pellet and wash and discard the ethanol.

20. Air-dry the pellet for 5-10 min. Resuspend the pellet in $11 \mu \mathrm{L}$ of TE buffer.

21. Dilute the DNA with TE buffer (as required) for downstream analysis.

Note: Steps 1-9 correspond to the NP method of crude genomic DNA extraction.

\subsection{DNA Quantification}

The quantity of genomic DNA isolated by each method was tested with a Qubit ${ }^{\text {TM }}$ dsDNA HS Assay Kit, following the manufacturers' procedures.

\subsection{DNA Quality Assessment}

The quality of extracted DNA was determined at $260 \mathrm{~nm}$ using the Eppendorf BioSpectrometer ${ }^{\circledR}$ fluorescence with $1 \mu \mathrm{L}$ of each sample, as described by the manufacturer. Agarose gel electrophoresis was used to further assess the gDNA quality in $0.8 \%$ agarose gel, visualizing the DNA using $0.5 \mu \mathrm{g} / \mathrm{mL}$ ethidium bromide in Tris/Borate/EDTA (TBE). 


\section{Optimized nuclear pellet method}

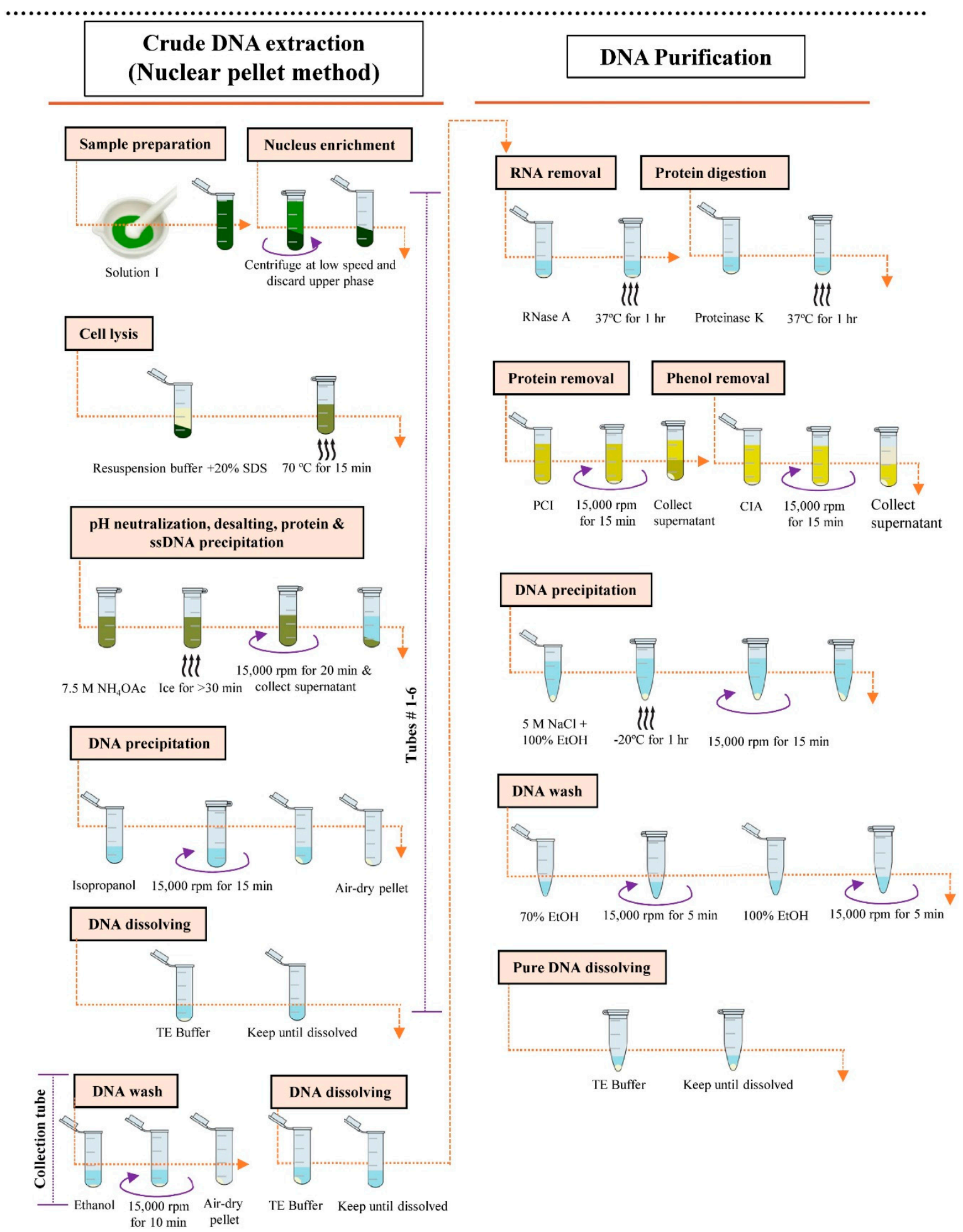

Figure 1. Schematic illustration of the procedures of genomic DNA extraction using the optimized nuclear pellet (NP) method.

\subsection{Quantification of Nuclear, Chloroplast, and Mitochondrial DNAs by qPCR}

The nuclear, chloroplast, and mitochondrial DNAs were quantified by quantitative real-time PCR (qPCR) according to our previous protocol [18]. The qPCR was performed using SsoFast EvaGreen Supermix (Bio-Rad) on a CFX96 real-time PCR system/C1000 Thermal Cycler (Bio-Rad). 
Two nanograms of plant DNA from each extraction method were used in a $10 \mu \mathrm{L}$ reaction mixture. The thermocycling conditions were denaturation at $98^{\circ} \mathrm{C}$ for $2 \mathrm{~min}$ and 39 cycles of $98^{\circ} \mathrm{C}$ for $2 \mathrm{~s}$ and $60{ }^{\circ} \mathrm{C}$ for $5 \mathrm{~s}$. All the primer sets used to analyze the genome copy number are listed in Supplementary Table S1. First, we calculated the copy ratios of nuclear DNA/chloroplast DNA genome and nuclear DNA/mitochondrial DNA genome by relative quantification ( $2^{-\Delta \Delta c t}$ method), and then each genome DNA content was quantified from the copy ratio and genome size (nuclear, 373,245,519 bp; plastid, 134,525 bp; mitochondrial, 490,520 bp).

\section{Results and Discussion}

In the current study, we optimized the existing nuclear pellet method [16] to improve gDNA purity for NGS library preparation (Figure 1). The optimization was based mainly on the incorporation of simple purification steps, such as proteinase K, RNase A, PCI, and CIA treatments for protein digestion and RNA, protein, and phenol removal, respectively. We added RNase A and proteinase $\mathrm{K}$ before the PCI and CIA extractions to obtain highly purified gDNA.

Our protocol resulted in a mean yield of $10.40 \mu \mathrm{g}$ gDNA/g fresh tissue (Table 1), significantly higher than the CTAB-based and QIAGEN DNeasy Plant Mini Kit extraction protocols. Due to the high gDNA yield, this protocol allows a downscaling of the amounts of leaf tissue and reagents used. The extracted gDNA obtained from the optimized protocol had an $A_{260} / A_{280}$ ratio of 1.87 and the absorbance showed a single peak at $260 \mathrm{~nm}$ (Table 1, Figure 2A), indicating that the gDNA was pure and contamination free.

Table 1. Comparison of the genomic DNA absorbance and yield of rice (Oryza sativa L.) tissue in the four different isolation protocols.

\begin{tabular}{cccc}
\hline Experimental Method & $\boldsymbol{A}_{\mathbf{2 6 0}} / \boldsymbol{A}_{\mathbf{2 8 0}}$ Ratio & $\boldsymbol{A}_{\mathbf{2 6 0}} / \boldsymbol{A}_{\mathbf{2 3 0}}$ Ratio & $\begin{array}{c}\text { DNA Yield }(\boldsymbol{\mu} \mathbf{g} / \mathbf{g} \text { Fresh } \\
\text { Tissue) }\end{array}$ \\
\hline CTAB-based & $2.06 \pm 0.10$ & $2.39 \pm 0.04$ & $6.59 \pm 0.80 \mathrm{c}$ \\
QIAGEN DNeasy Plant Mini Kit & $1.91 \pm 0.03$ & $2.31 \pm 0.03$ & $9.03 \pm 1.50 \mathrm{~b}$ \\
Nuclear pellet & $2.08 \pm 0.01$ & $2.46 \pm 0.02$ & $11.78 \pm 1.38 \mathrm{a}$ \\
Optimized nuclear pellet & $1.87 \pm 0.02$ & $2.26 \pm 0.05$ & $10.40 \pm 1.32 \mathrm{ab}$ \\
\hline
\end{tabular}

DNA absorbance was determined by Eppendorf BioSpectrometer ${ }^{\circledR}$ fluorescence. Quantification of DNA was assessed using the Qubit ${ }^{\mathrm{TM}}$ dsDNA HS Assay Kit. Data are presented as mean \pm SD of three biological replicates. Values with the same letter within a column are not statistically different (Duncan's multiple range test, $p<0.05$ ).

The integrity of the gDNA isolated by each method was also evaluated using $0.8 \%$ agarose gel electrophoresis. The gDNA obtained from the optimized NP method gave a clear, high-molecular-weight band with little or no smearing (Figure 2B). In contrast, the gDNAs of the CTAB-based, QIAGEN DNeasy Plant Mini Kit, and NP methods showed substantial smearing, indicating degradation of gDNA. The above results clearly demonstrate that improved DNA yield, quality, and integrity were obtained through optimization of the NP method. To purify the genomic DNA, the optimized NP method required $2 \mathrm{~h}$ more than the NP method (Supplementary Table S2).

We used qPCR to determine the genome relative abundance in each extraction. Although the optimized NP method slightly increased the nuclear DNA purity, the extracted DNA still contained the high copy number of organelle DNA (chloroplast and mitochondrial DNA), suitable for general NGS analysis (Figure 3A,B). 
A
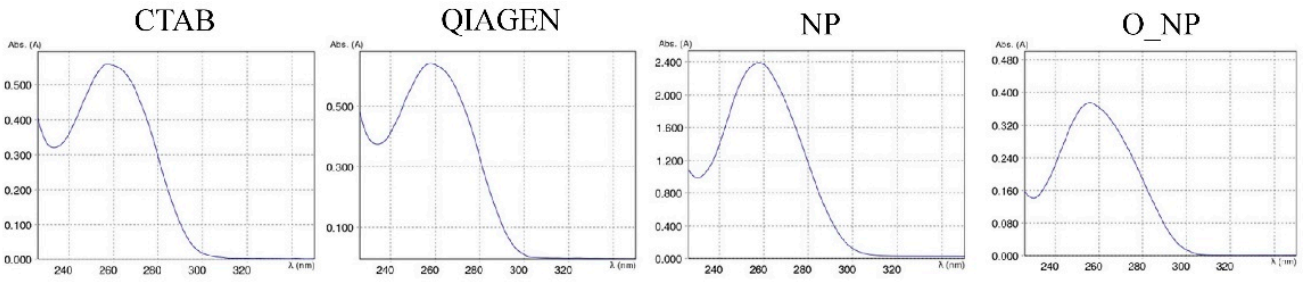

B

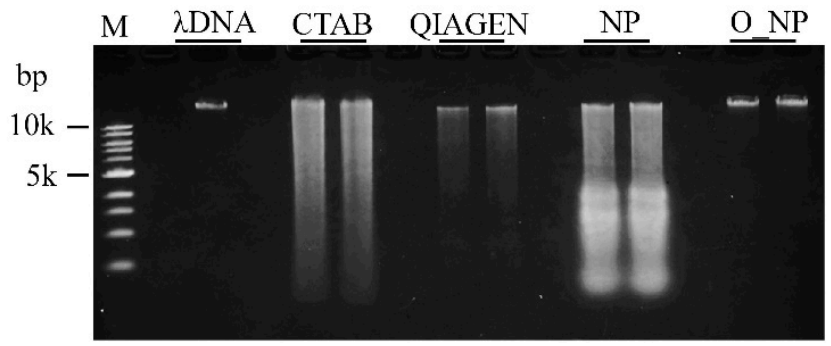

Figure 2. Genomic DNA quality assessment. Genomic DNA from young leaves of rice (Oryza sativa L.) plant was extracted by the traditional hexadecyltrimethylammonium bromide (CTAB)-based (CTAB), QIAGEN DNeasy Plant Mini Kit (QIAGEN), NP, and optimized NP (O_NP) methods. (A) Comparison of the absorbance profile of genomic DNA at different wavelengths by Eppendorf BioSpectrometer ${ }^{\circledR}$ fluorescence. (B) Comparison of genomic DNA integrity using agarose gel electrophoresis. DNA was resolved by electrophoresis in a $0.8 \%$ agarose gel and visualized using an ethidium bromide stain. $\mathrm{M}$ represents $1 \mathrm{~kb}$ DNA ladder (Toyobo Co., Ltd, Osaka, Japan).

A

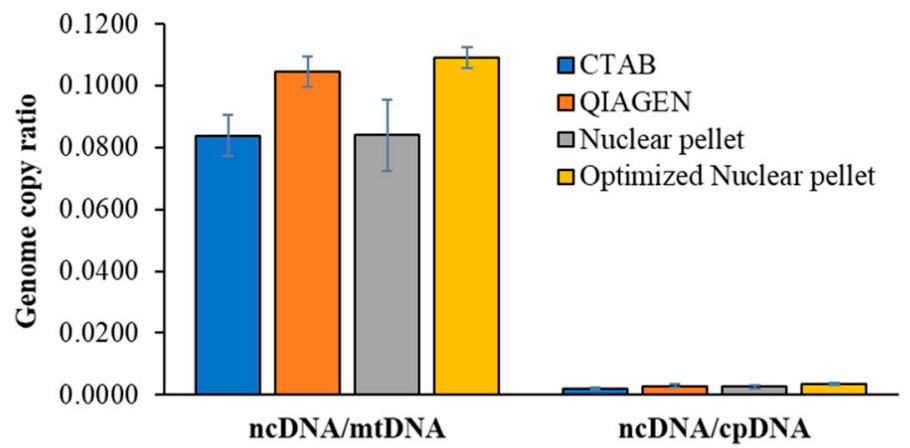

B

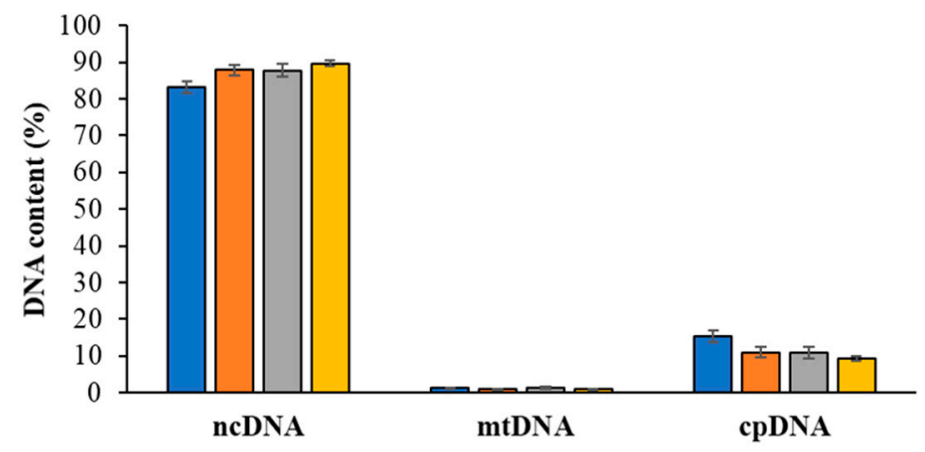

Figure 3. Comparison of genome relative abundance using qPCR. Genomic DNA from young leaves of rice (Oryza sativa L.) plant was extracted by the traditional CTAB-based (CTAB), QIAGEN DNeasy Plant Mini Kit (QIAGEN), NP, and optimized NP methods. Genome copy ratio (A) and DNA contents (B) were assessed according to Takamatsu et al. [18]. ncDNA, mtDNA, and cpDNA represent nuclear DNA, mitochondrial DNA, and chloroplast DNA, respectively. Data are presented as mean \pm SD of three independent biological replicates from each extraction method. 
Furthermore, we extracted DNAs from Yukinko-mai and introgressed rice plants using the optimized NP method for whole-genome sequencing [19]. The genomic DNA samples were sent to Macrogen Japan (http://www.macrogen-japan.co.jp/), where both the samples passed the stringent QC requirements (Table 2). The gDNAs were successfully sequenced on the Illumina Hiseq X Ten platform with NGS libraries prepared by the TruSeq DNA PCR-Free Library Prep Kit (Illumina, Inc., San Diego, CA, USA). In total, we obtained 200,938,541 (Yukinko-mai, DRR151852) and 232,059,326 (introgressed line, DRR151851) paired-end 150 bp reads (Figure 4).

We removed low-quality reads and trimmed low-quality bases using Trimmomatic v. 0.33 software [20] and assessed the quality of our sequenced data. Figure 4 shows that Phred quality scores (which indicate base calling accuracy) were high even in the latter half of read2, resulting in a high number of pairs of reads surviving the QC process. This result indicates that the optimized NP method provides accurate base calling and high read yields in the Illumina sequencing platform. These days, long-read sequencers such as PacBio RSII/Sequel and Oxford Nanopore Technologies provide powerful applications in de novo sequencing assembly and accurate structural variant (SV) analysis [21-23]. They also resolve breakpoints and repetitive regions that are insufficiently characterized using short-read sequencing technologies [24]. In addition, Linked Read Sequencing (10X Genomics Chromium Technology) is capable of obtaining haplotype-phased genome assembly, SNP/INDELs, SVs, and copy number variants (CNVs) [22,25]. These technologies require high-quality intact DNA of high molecular weight [6,7]. We consider that the gDNA obtained using our modified NP protocol fulfills the stringent requirements of these sequencing platforms better than conventional DNA extraction methods and will improve the analytical genomics of any plant species.

Table 2. Summary of DNA quality control (QC) results from Macrogen.

\begin{tabular}{cccc}
\hline Sample Name & $\begin{array}{c}\text { DNA Submitted } \\
(\mathbf{n g} / \boldsymbol{\mu L} \text { TE Buffer) }\end{array}$ & $\begin{array}{c}\text { Total DNA } \\
\text { Submitted }(\boldsymbol{\mu g})\end{array}$ & $\begin{array}{c}\text { NGS Quality } \\
\text { Control Results }\end{array}$ \\
\hline Yukinko-mai & 330.7 & 5.29 & Passed \\
Introgressed line $\left(\mathrm{BC}_{3} \mathrm{~F}_{2}\right)$ & 256.8 & 4.11 & Passed \\
\hline
\end{tabular}

DNA was extracted from young leaves of rice (Oryza sativa L.) plant. DNA QC based on measurement of absorbance $\left(A_{260} / A_{280}\right.$ ratio), quantification of DNA using Picogreen method using Victor $\mathrm{X} 2{ }^{\circledR}$ fluorometry, and $1.0 \%$ agarose gel electrophoresis. Passed: Samples proceeded to the library construction step automatically. 

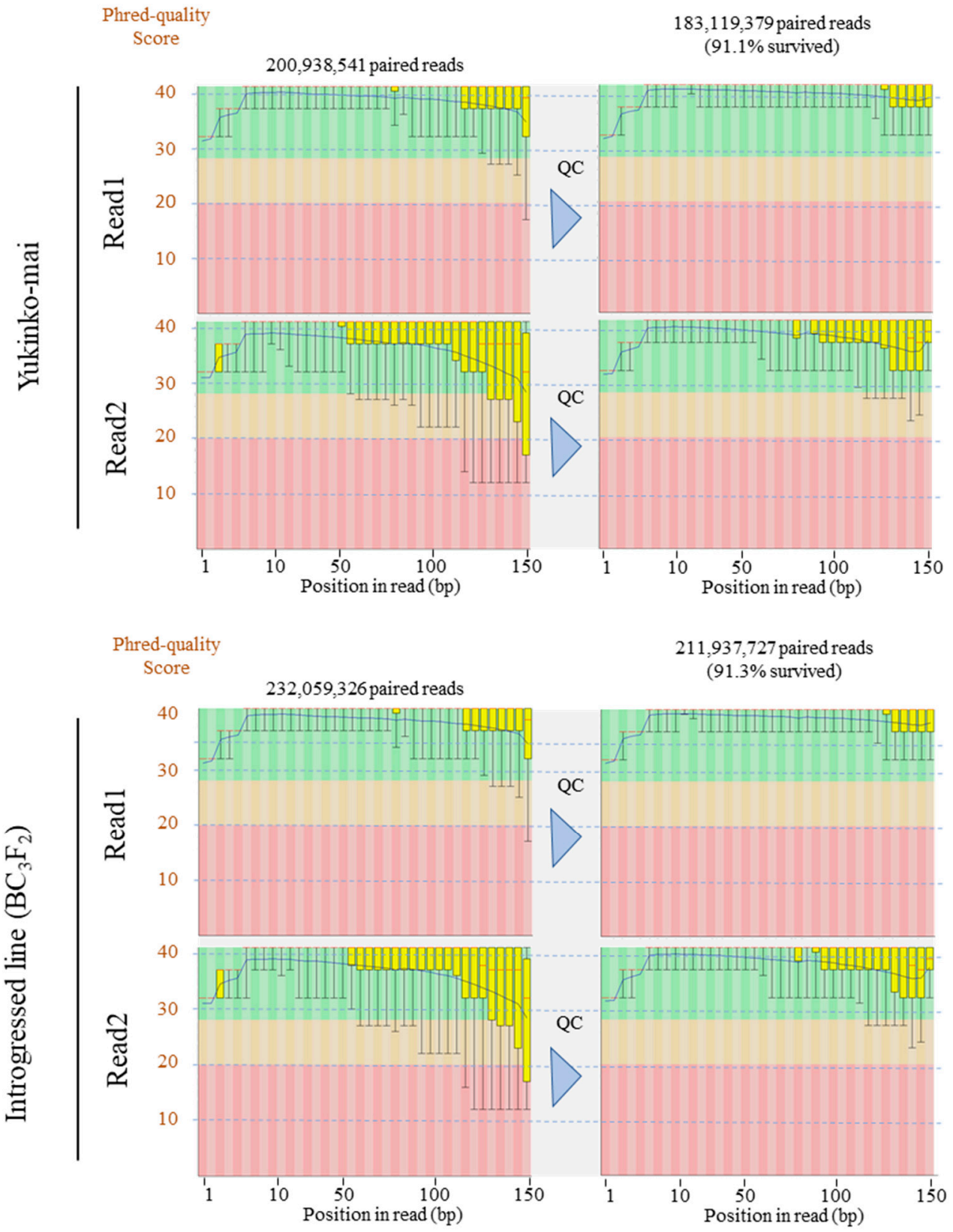

Figure 4. Per base sequence quality of Illumina sequencing reads. Next-generation sequencing (NGS) library was constructed using the gDNA from young leaves of rice (Oryza sativa L.) plant extracted via optimized NP protocol. Phred quality scores across paired-end reads before (left columns) and after (right columns) QC are shown in box plots. The blue and red lines represent the mean quality and median value, respectively. The yellow box represents the first quartile and third quartile. The whiskers extend from the ends of the box to the top $10 \%$ and $90 \%$ values. The background of the graph in the $y$-axis shows sequence quality. Green, very good quality calls; orange, reasonable quality; red, poor quality. Quality control was performed using Trimmomatic v. 0.33 software [20] with the following parameters: SLIDINGWINDOW: 8:20; TRAILING: 30; MINLEN: 70.

\section{Conclusions}

Our optimized nuclear pellet method is very efficient and reliable in extracting high-quality gDNA and is appropriate for targeted NGS library preparation followed by sequencing. This report provides a reliable step-by-step guide for molecular biologists on the isolation of high yields of pure gDNA from fresh leaf tissues of rice. 
Supplementary Materials: The following are available online at http://www.mdpi.com/2409-9279/2/2/54/s1, Supplementary Table S1: List of primers [18] used in qPCR for genome copy analysis; Supplementary Table S2: Times required for CTAB-based, QIAGEN DNeasy Plant Mini Kit, nuclear pellet and optimized nuclear pellet methods of extracting genomic DNA. The time required was calculated with 4 samples for each extraction method.

Author Contributions: K.I. designed the experimental protocol; M.M.R. and M.A. performed the experiments; T.T. carried out the QC analysis of sequencing data; K.K. and T.M. contributed to the conception of the work; M.M.R., T.T., and M.A. wrote the article with contributions from all the authors; K.I. supervised the research.

Funding: This research is funded by the Grant for Promotion of KAAB Projects (Niigata University) from the Ministry of Education, Culture, Science and Technology (Japan).

Acknowledgments: Computations were performed on the NIG supercomputer at the ROIS National Institute of Genetics.

Conflicts of Interest: The authors declare that the research was conducted in the absence of any commercial or financial relationships that could be construed as potential conflicts of interest.

\section{References}

1. Egan, A.N.; Schlueter, J.; Spooner, D.M. Applications of next-generation sequencing in plant biology. Am. J. Bot. 2012, 99, 175-185. [CrossRef] [PubMed]

2. Healey, A.; Furtado, A.; Cooper, T.; Henry, R.J. Protocol: A simple method for extracting next-generation sequencing quality genomic DNA from recalcitrant plant species. Plant Methods 2014, 10, 21. [CrossRef] [PubMed]

3. Anderson, C.B.; Franzmayr, B.K.; Hong, S.W.; Larking, A.C.; van Stijn, T.C.; Tan, R.; Moraga, R.; Faville, M.J.; Griffiths, A.G. Protocol: A versatile, inexpensive, high-throughput plant genomic DNA extraction method suitable for genotyping-by-sequencing. Plant Methods 2018, 14, 75. [CrossRef] [PubMed]

4. Kasem, S.; Rice, N.; Henry, R. DNA extraction from plant tissue. In Plant Genotyping II SNP Technol; Henry, R.J., Ed.; CAB International: Wallingford, Oxfordshire, UK, 2008; pp. 219-271.

5. Abdel-Latif, A.; Osman, G. Comparison of three genomic DNA extraction methods to obtain high DNA quality from maize. Plant Methods 2017, 13, 1. [CrossRef] [PubMed]

6. Rhoads, A.; Au, K.F. PacBio Sequencing and Its Applications. Genomics. Proteomics Bioinf. 2015, 13, $278-289$. [CrossRef] [PubMed]

7. Mayjonade, B.; Gouzy, J.; Donnadieu, C.; Pouilly, N.; Marande, W.; Callot, C.; Langlade, N.; Muños, S. Extraction of high-molecular-weight genomic DNA for long-read sequencing of single molecules. Biotechniques 2016, 61, 2003-2005. [CrossRef] [PubMed]

8. Doyle, J.J.; Doyle, J.L. A rapid DNA isolation procedure for small quantities of fresh leaf tissue. Phytochem. Bull. 1987, 19, 11-15.

9. Xu, X.; Kawasaki, S.; Fujimura, T.; Wang, C. A protocol for high-throughput extraction of DNA from rice leaves. Plant Mol. Biol. Report. 2005, 23, 291-295. [CrossRef]

10. Whitlock, R.; Hipperson, H.; Mannarelli, M.; Burke, T. A high-throughput protocol for extracting high-purity genomic DNA from plants and animals. Mol. Ecol. Resour. 2008, 8, 736-741. [CrossRef]

11. Pereira, J.C.; Chaves, R.; Bastos, E.; Leitão, A.; Guedes-Pinto, H. An efficient method for genomic DNA extraction from different molluscs species. Int. J. Mol. Sci. 2011, 12, 8086-8095. [CrossRef]

12. Telfer, E.; Graham, N.; Stanbra, L.; Manley, T.; Wilcox, P. Extraction of high purity genomic DNA from pine for use in a high-throughput Genotyping Platform. New Zeal. J. For. Sci. 2013, 43, 3. [CrossRef]

13. Werth, S.; Reynisdóttir, S.; Gudmundsson, H.; Andrésson, Ó.S. A Fast and Inexpensive High-Throughput Protocol for Isolating High Molecular Weight Genomic DNA from Lichens. Herzogia 2016, 29, 610-616. [CrossRef]

14. Minas, K.; McEwan, N.R.; Newbold, C.J.; Scott, K.P. Optimization of a high-throughput CTAB-based protocol for the extraction of qPCR-grade DNA from rumen fluid, plant and bacterial pure cultures. FEMS Microbiol. Lett. 2011, 325, 162-169. [CrossRef] [PubMed]

15. Simbolo, M.; Gottardi, M.; Corbo, V.; Fassan, M.; Mafficini, A.; Malpeli, G.; Lawlor, R.T.; Scarpa, A. DNA Qualification Workflow for Next Generation Sequencing of Histopathological Samples. PLoS ONE 2013, 8. [CrossRef] [PubMed]

16. Walbot, V.; Warren, C. Regulation of $M u$ element copy number in maize lines with an active or inactive Mutator transposable element system. Mol. Gen. Genet. 1988, 211, 27-34. [CrossRef] 
17. Shimamoto, K.; Terada, R.; Izawa, T.; Fujimoto, H. Fertile transgenic rice plants regenerated from transformed protoplasts. Nature 1989, 338, 274-276. [CrossRef]

18. Takamatsu, T.; Baslam, M.; Inomata, T.; Oikawa, K.; Itoh, K.; Ohnishi, T.; Kinoshita, T.; Mitsui, T. Optimized Method of Extracting Rice Chloroplast DNA for High-Quality Plastome Resequencing and de Novo Assembly. Front. Plant Sci. 2018, 9, 266. [CrossRef]

19. Rana, M.M.; Takamatsu, T.; Baslam, M.; Kaneko, K.; Itoh, K.; Harada, N.; Sugiyama, T.; Ohnishi, T.; Kinoshita, T.; Takagi, H.; et al. Salt Tolerance Improvement in Rice through Efficient SNP Marker-Assisted Selection Coupled with Speed-Breeding. Int. J. Mol. Sci. 2019, 20, 2585. [CrossRef]

20. Bolger, A.M.; Lohse, M.; Usadel, B. Trimmomatic: A flexible trimmer for Illumina sequence data. Bioinformatics 2014, 30, 2114-2120. [CrossRef]

21. Jain, M.; Koren, S.; Miga, K.H.; Quick, J.; Rand, A.C.; Sasani, T.A.; Tyson, J.R.; Beggs, A.D.; Dilthey, A.T.; Fiddes, I.T.; et al. Nanopore sequencing and assembly of a human genome with ultra-long reads. Nat. Biotechnol. 2018, 36, 338-345. [CrossRef]

22. Seo, J.-S.; Rhie, A.; Kim, J.; Lee, S.; Sohn, M.-H.; Kim, C.-U.; Hastie, A.; Cao, H.; Yun, J.-Y.; Kim, J.; et al. De novo assembly and phasing of a Korean human genome. Nature 2016, 538, 243-247. [CrossRef] [PubMed]

23. Huddleston, J.; Chaisson, M.J.P.; Steinberg, K.M.; Warren, W.; Hoekzema, K.; Gordon, D.; Graves-Lindsay, T.A.; Munson, K.M.; Kronenberg, Z.N.; Vives, L.; et al. Discovery and genotyping of structural variation from long-read haploid genome sequence data. Genome Res. 2017, 27, 677-685. [CrossRef] [PubMed]

24. Mitsuhashi, S.; Nakagawa, S.; Takahashi Ueda, M.; Imanishi, T.; Frith, M.C.; Mitsuhashi, H. Nanopore-based single molecule sequencing of the D4Z4 array responsible for facioscapulohumeral muscular dystrophy. Sci. Rep. 2017, 7, 14789. [CrossRef] [PubMed]

25. Colle, M.; Leisner, C.P.; Wai, C.M.; Ou, S.; Bird, K.A.; Wang, J.; Wisecaver, J.H.; Yocca, A.E.; Alger, E.I.; Tang, H.; et al. Haplotype-phased genome and evolution of phytonutrient pathways of tetraploid blueberry. Gigascience 2019, 8. [CrossRef] [PubMed]

(C) 2019 by the authors. Licensee MDPI, Basel, Switzerland. This article is an open access article distributed under the terms and conditions of the Creative Commons Attribution (CC BY) license (http://creativecommons.org/licenses/by/4.0/). 